\title{
Tuberculosis and AIDS Co-Morbidity in Brazil: Linkage of the Tuberculosis and AIDS Databases
}

\author{
Angelica Espinosa Miranda ${ }^{1}$, Jonathan E. Golub ${ }^{2}$, Francisca de Fátima Lucena ${ }^{3}$, Ethel Noia Maciel ${ }^{1}$, Maria de Fátima Gurgel ${ }^{4}$ \\ and Reynaldo Dietze ${ }^{1}$ \\ ${ }^{1}$ Center of Infectious Diseases, Federal University of Espírito Santo, Vitória, ES; ${ }^{2}$ Center for TB Research, Johns Hopkins University, USA; \\ ${ }^{3}$ National Program of STD/AIDS, Ministry of Health, Brasília, DF, Brazil; ${ }^{4}$ Department of Epidemiology, Secretaria Estadual de Saúde \\ do Espírito Santo, Vitória, ES, Brazil
}

\begin{abstract}
This study evaluated differences in AIDS patients with and without tuberculosis (TB) in Espírito Santo State, Brazil. Standard regional AIDS (SINAN, SISCEL, SICLOM and SIM) and tuberculosis (SINAN) databases were used. TB and AIDS databases were linked using Reclink software, version 3, with SPSS software support to identify co-infected cases. Data from July 2000 to June 2006 in Espírito Santo State were linked. The results showed 3,523 adult AIDS cases and 9,958 adult TB cases resulted in 430 co-infected patients, who were compared to 1,290 AIDS patients who never developed TB. Among 430 co-infected patients, TB was diagnosed first in 223 (51.9\%), AIDS was first in $44(10.2 \%)$, and AIDS and TB were diagnosed concurrently in 163 (37.9\%). Median age did not differ between co-infected cases (36 years (interquartile range [IQR] 29-43) and non-co-infected cases (34 years; IQR 28-42). Pulmonary tuberculosis was diagnosed in 239 (55.6\%); 109 (25.3\%) had extra-pulmonary TB and 82 (19.1\%) had both presentations. In the final logistic regression model, living in a metropolitan area [Odds Ratio (OR) $=1.43(95 \%$ Confidence Interval (CI) 1.05-1.95)], education $\leq 3$ years [OR=3.03 (95\%CI 1.56-5.88)] and CD4 counts $\leq 200 / \mathrm{mm}^{3}$ [OR=1.14 (95\%CI 1.09-1.18)] were associated with co-infection. This report emphasizes the significance of tuberculosis among AIDS cases in Brazil, and highlights the importance of evaluating secondary data for purposes of improving data quality and developing public health interventions.

Key-Words: AIDS, tuberculosis, co-infection, secondary data.
\end{abstract}

HIV-infected patients are more likely to experience endogenous reactivation of a latent tuberculosis (TB) infection or rapidly progress from recent TB infection to TB disease than HIV-negative persons [1-3]. Thus, HIV-infected patients represent a source of potential TB index cases, which may increase incidence of TB disease and infection in the community $[4,5]$.

There is often lack of communication between AIDS and TB programs and co-infected patients are often not detected until death, highlighting a failure of the health system to detect, diagnosis and treat these related diseases. Co-infection rates have been reported as high as $51 \%$ in mortality surveillance systems in Rio de Janeiro, Brazil [6], and more recently, an AIDS and TB database registry match found $18.5 \%$ of AIDS patients between 1995 and 2004 to be co-infected in Rio [7]. HIV-infected patients are at increased risk for reactivation of a latent TB infection [8] due to a deficient immunological response [9], while AIDS is a strong risk factor for death in TB patients [1,8]. Mortality in co-infected patients is commonly related to delays in diagnosis as HIV patients may postpone seeking health care to avoid receiving an AIDS diagnosis [10].

In Brazil, 506,499 cases of AIDS have already been reported through December 2007. Incidence increased through the mid-

Received on 10 October 2008; revised 11 February 2009.

Address for correspondence: Dr. Angélica Espinosa Miranda. Núcleo de Doenças Infecciosas, Universidade Federal do Espírito Santo. Avenida Marechal Campos, 1468. Maruípe, Vitória - ES. Zip code: 29040-091. E-mail: espinosa@ndi.ufes.br. Phone: (5527) 3335-7210. Fax: (5527) 3335-7504.

The Brazilian Journal of Infectious Diseases 2009;13(2):137-141. (C) 2009 by The Brazilian Journal of Infectious Diseases and Contexto Publishing. All rights reserved.
1990 s with a peak of $19 / 100,000$ in 1998 . Approximately $80 \%$ of AIDS patients inhabit the South East and South regions of Brazil. The South East, where Espirito Santo State is located, is the most affected since the beginning of the epidemic but, despite the high incidence rate, the number of AIDS cases in the region remains stable at approximately 17,000 per year [11]. In 2007, 602 AIDS cases were reported in Espírito Santo State for an incidence of 7.2/100,000. TB incidence in the State was 56/100,000 in 2007, similar to the national average of 54.7/ $100,000[11]$.

The objective of this study was to utilize and link existing TB and AIDS surveillance databases to evaluate the profile of TB-AIDS co-infected cases as defined by sex, age, immunity and death. These data provide an updated account of TBAIDS co-infection in the State that will inform prevention and control programs for these two diseases.

\section{Material and Methods}

Study Design

A comparative study was designed to identify differences among AIDS patients with or without tuberculosis detected through linkage of regional comprehensive databases. These databases support the improvement of health care systems in Brazil by increasing the capacity of health care workers to make decisions based on accurate information.

\section{Data Collection and Management Plan}

Linkage of TB and AIDS databases was performed using Reclink software, version 3 [12], with SPSS software support to identify co-infected cases. Data from Espírito Santo State, July 2000 to June 2006, were linked. The AIDS database included data from SINAN (Morbidity Surveillance Database), SIM (Mortality Surveillance Database), SISCEL (AIDS 
Laboratory Database) and SICLOM (Antiretroviral Control System Database).

Surveillance databases were compared using patient name, mother's name and date of birth with a math probability of 92\% for names and $90 \%$ for dates. Block variables with patient's first and last names and gender were created to optimize the procedure and identify patients present in both databases. These data were checked individually to confirm co-infection, exclude duplicity and complete missing information. Any diagnoses of TB and AIDS within 90 days of each other were considered to be diagnosed at the same time. Patients $<14$ years old were excluded. For each TBAIDS co-infected case, the next three AIDS patients that were never reported to be co-infected with TB were chosen for comparison from the AIDS database.

\section{Statistical Methods}

Standard descriptive statistical analyses were performed, including frequency distributions for categorical data and calculation of medians and interquartile ranges for continuous variables. Prevalence of TB-AIDS co-infection was calculated for each risk factor of interest and odds ratios (OR) and 95\% confidence intervals (CI) estimated the strength of associations. Variables significant at $\mathrm{p}<0.15$ in bivariate analyses, and additional variables based on known a priori associations, were considered in the multivariate analysis. The main risk factors were assessed by stepwise multiple logistic regression models, with $15 \%$ as the critical p-value for variable entry and $10 \%$ as the criterion for variable elimination.

\section{Results}

Three AIDS databases and the national mortality surveillance database were merged, cleaned and validated by the Brazilian Ministry of Health prior to our linkage with the tuberculosis database. This preliminary process added 887 AIDS cases to the 2,908 reported in the Morbidity Surveillance System (SINAN-AIDS). There were a total of 3,795 AIDS cases in the 4 databases from 2000 to 2006. After eliminating AIDS cases $<14$ years of age, 3,523 AIDS patients remained for linkage with 9,958 TB cases in the State TB database. Among these 3,523 AIDS cases, TB-AIDS co-infection was found in 430 [12.2\% (95\%CI 11.1\%-13.3\%)] records. Among co-infected cases, TB was the first infection in 223 (51.9\%), AIDS was first in 44 (10.2\%) cases, and in 163 (37.9\%) AIDS and TB were diagnosed at the same time. Regarding TB presentation in these patients, 239 (55.6\%) were pulmonary, 109 (25.3\%) extrapulmonary and 82 (19.1\%) had both presentations. Lymphatic TB was the most frequent extra-pulmonary presentation (23.2\%). Approximately 90\% of all co-infected cases were diagnosed with TB within one year of AIDS diagnosis.

Demographic variables of AIDS cases with and without TB are shown in Table 1. Median age in co-infected cases was 36 (interquartile range [IQR] 29; 43) years and 34 (IQR 28; 42) years among AIDS cases. Co-infected cases were more likely to be male, live in a metropolitan area, and be less educated in bivariate analysis. Co-infected patients were also more likely to be reported in the AIDS database (SINAN-AIDS) compared to AIDS patients not co-infected with TB. Table 2 shows behavioral and clinical variables of AIDS cases with and without TB. Co-infected patients were more likely to have a CD4 count $\leq 200$. No other behavioral or clinical factors were significantly different.

In the final logistic regression model, living in a metropolitan area [adjusted (a)OR=1.43 (95\%CI 1.05-1.95)], lower education (up to three years) $[\mathrm{aOR}=3.03$ (95\%CI 1.565.88)] and lower CD4 counts [aOR=1.14 (95\%CI 1.09-1.18)] were associated to co-infected cases.

\section{Discussion}

This study investigating the prevalence of co-infection of TB and AIDS in Espirito Santo State, Brazil found that 12.2\% of AIDS cases between 2000 and 2006 were co-infected with $\mathrm{TB}$, slightly less than recently reported in Rio de Janeiro, Brazil [7]. An increased association with TB-AIDS co-infection was seen among AIDS patients living in the metropolitan area, and those with less education and lower baseline CD4 counts. These results are in agreement with other studies in Brazil [13$16]$ and other areas $[15,16]$.

It is important to use secondary data for assessing health programs and for implementing cost-effective health strategies. However, the data must be analyzed and interpreted appropriately [18] and there is an underlying assumption that data collection is relatively complete. The databases used in this analysis were developed to support the improvement of health care systems in Brazil by increasing the capacity of health care workers to make decisions based on accurate surveillance information. Previous investigators in Brazil have used these techniques to merge databases for improving surveillance information and implementing health strategies [12,19-21]. We found that $23 \%$ of all AIDS cases used to initiate our linkage process were not reported to the national AIDS database (SINAN-AIDS) and a large proportion of patients had missing data regarding behavioral risk factors and CD4 cell counts. Such underreporting of patients and patient data can have a dramatic impact on programs and interventions informed by these estimates.

Lower education was an important factor in TB-AIDS cases found in this study. In the last decade, the AIDS epidemic in Brazil has reached new population groups and cities where it had not been recorded previously, affecting the less privileged social segments in the country $[16,22]$. These populations have historically been plagued with high TB rates; thus, the introduction of the AIDS epidemic has worsened the TB problem. Our data suggests that TB-AIDS cases are poorer than AIDS cases without TB, using education as a proxy measure for poverty. Impoverished areas arise out of a sociopolitical context on differential access to power and resources. In this context, poverty is associated with little or no power, and extremely limited resources. Thus, poverty dramatically increases risk for HIV/AIDS and TB through increased 
Table 1. Demographic data of AIDS cases with and without TB in Espírito Santo State, Brazil.

\begin{tabular}{|c|c|c|c|}
\hline Variables & $\begin{array}{l}\text { AIDS without TB } \\
\mathrm{N}(\%)\end{array}$ & $\begin{array}{l}\text { AIDS with TB } \\
\mathrm{N}(\%)\end{array}$ & OR $(95 \% C I)$ \\
\hline \multicolumn{4}{|l|}{ Living in } \\
\hline Metropolitan area & $1,092(76.0)$ & $345(24.0)$ & $1.4(1.03-1.80)^{2}$ \\
\hline Other & $198(70.0)$ & $85(30.0)$ & 1 \\
\hline \multicolumn{4}{|l|}{ Surveillance at } \\
\hline Metropolitan area & 1,237 (74.8) & $417(25.2)$ & $1.4(0.74-2.54)$ \\
\hline Other & $53(80.3)$ & $13(19.7)$ & 1 \\
\hline \multicolumn{4}{|l|}{ Age (years) } \\
\hline $13-24$ & $163(79.5)$ & $42(20.5)$ & 1 \\
\hline $25-34$ & $494(75.9)$ & $157(24.1)$ & $0.9(0.49-1.65)$ \\
\hline $35-44$ & $404(74.7)$ & $137(25.3)$ & $1.1(0.64-1.65)$ \\
\hline $45-54$ & $163(68.5)$ & $75(31.5)$ & $1.2(0.68-2.03)$ \\
\hline 55 or more & $66(77.6)$ & $19(22.4)$ & $1.6(0.90-2.85)$ \\
\hline \multicolumn{4}{|l|}{ Sex } \\
\hline Male & $711(70.8)$ & $293(29.2)$ & $1.7(1.38-2.19)^{1}$ \\
\hline Female & $579(80.9)$ & $137(19.1)$ & 1 \\
\hline \multicolumn{4}{|l|}{ Education (years) } \\
\hline Illiterate & $67(64.4)$ & $37(35.6)$ & $2.5(1.24-5.25)^{2}$ \\
\hline $1-3$ & $237(64.8)$ & $129(35.2)$ & $2.5(1.33-4.75)^{2}$ \\
\hline $4-7$ & $461(74.1)$ & $161(25.9)$ & $1.6(0.86-3.01)$ \\
\hline $8-11$ & $277(83.7)$ & $54(16.3)$ & $0.9(0.46-1.75)$ \\
\hline 12 or more & $60(82.2)$ & 13(17.8\%) & 1 \\
\hline Missing values & $188(83.9)$ & $36(16.1 \%)$ & $0.9(0.44-1.78)$ \\
\hline \multicolumn{4}{|l|}{ AIDS Surveillance } \\
\hline SINAN & $997(73.6)$ & $357(26.4)$ & $1.4(1.08-1.91)^{2}$ \\
\hline Other databases* & $293(80.1)$ & $73(19.9)$ & 1 \\
\hline
\end{tabular}

exposure and greater vulnerability to infection [17,23,24]. Once infected, capacity to cope with the consequences of disease is diminished among poorer people because of barriers to access of preventive, diagnostic and curative services [17].

Efforts to prevent and control HIV/AIDS and TB in impoverished populations are not likely to succeed outside of an integrated approach that seeks to reduce the underlying social inequities. A challenge in addressing AIDS and TB in informal settlements is how to strategically utilize potential opportunities to create lasting improvements in urban areas with impoverished conditions so they are better equipped to reduce vulnerability to HIV/AIDS and TB, and to access the full range of health care services to prevent, treat and mitigate these diseases.

The present study also found an association between TBAIDS co-infection and low CD4 cell counts, an association commonly observed in Brazil [25] and other areas [26]. TB patients who are HIV-infected with low CD4 cell counts frequently have chest radiographic findings that are not typical of pulmonary TB. In particular, they are more likely than TB patients who are not HIV-infected to have mediastinal adenopathy and less likely to have upper-lobe infiltrates and cavities [3,18]. Atypical radiographic findings increase the potential for delays in diagnosis, which increases transmission among patients and their contacts [27].
The most important limitation of this study is the definition of TB-AIDS co-infection, which includes patients diagnosed with TB prior to AIDS, AIDS prior to TB and patients diagnosed with both at the same time. By combining this group and comparing it to AIDS patients who never developed TB, we are not able to detect differences specific to one of these groups. Another limitation is that we only have dates for AIDS diagnoses, and not HIV-diagnoses. A TB diagnosis among an HIV-infected patient in Brazil is not an AIDS defining illness on its own. Thus, the timing of HIV, AIDS and TB is difficult to determine, which lead to the decision to combine these patient groups.

The most important strength of this study was the inclusion of four different databases that maximized the number of AIDS patients included in the linkage process. This approach revealed a significant underreporting problem of AIDS cases, in addition to a surprising number of individuals with missing data regarding behavioral risk factors and CD4 cell count data. These findings highlight the need for better surveillance procedures in AIDS patients, and further training and education of health care providers to ensure more complete and accurate data collection. These measures are a minimal expectation if surveillance databases are to be used for program development. 
Table2. Behavioral and clinical data of AIDS cases with and without TB in Espírito Santo State, Brazil.

\begin{tabular}{|c|c|c|c|}
\hline Variables & AIDS with TB & AIDS without TB & Pvalue \\
\hline \multicolumn{4}{|l|}{ Heterosexual } \\
\hline Yes & $241(24.2 \%)$ & $753(75.8 \%)$ & 0.481 \\
\hline No & $97(26.2 \%)$ & 273(73.8\%) & \\
\hline Unknown & $92(25.8 \%)$ & $264(74.1 \%)$ & \\
\hline \multicolumn{4}{|l|}{ Bi/homosexual } \\
\hline Yes & $67(25.0 \%)$ & $201(75.0 \%)$ & 0.915 \\
\hline No & $271(24.7 \%)$ & $825(75.3 \%)$ & \\
\hline Unknown & $92(25.8 \%)$ & $264(74.2 \%)$ & \\
\hline \multicolumn{4}{|l|}{ IV Drug abuse } \\
\hline Yes & $38(29.5 \%)$ & $91(70.5 \%)$ & 0.400 \\
\hline No & $300(24.3 \%)$ & $935(75.7 \%)$ & \\
\hline Unknown & $92(25.8 \%)$ & $264(74.2 \%)$ & \\
\hline \multicolumn{4}{|l|}{ CD4 counts } \\
\hline Up to 200 & $182(25.6 \%)$ & $526(74.4 \%)$ & 0.000 \\
\hline More than 200 & 133(18.3\%) & $594(81.7 \%)$ & \\
\hline Missing values & $115(40.6 \%)$ & $170(59.4 \%)$ & \\
\hline \multicolumn{4}{|l|}{ Death } \\
\hline Yes & $34(20.0 \%)$ & $136(80.0 \%)$ & 0.135 \\
\hline No & $396(25.5 \%)$ & $1,154(74.5 \%)$ & \\
\hline
\end{tabular}

This report emphasizes the significance of tuberculosis among AIDS cases in Brazil, and highlights the importance of evaluating secondary data for purposes of improving data quality and developing public health interventions. TB surveillance among HIV patients contributes to the development of more coordinated and collaborative approaches for controlling both epidemics. The combination of various surveillance components and data sources improves the knowledge of HIV and TB epidemics within groups at higher risk for both infections. TB-AIDS co-infection is a significant problem in our region that needs a targeted and informed plan of action.

\section{Acknowledgments}

This study was supported by the Innovative approaches for tuberculosis control in Brazil: Grant \#5 U2R TW006883-02, NIH AI66994 Fogarty International Center/USNIH \#U2RTW006885 ICOHRTA and Dr. Golub was supported by the National Institutes of Health grant AI066994.

\section{References}

1. Pablos-Méndez A., Sterling T.R., Frieden T.R. The relationship between delayed or incomplete treatment and all-cause mortality in patients with tuberculosis. JAMA 1996;276:1223-8.

2. Gledovic Z., Jovanovic M., Pekmezovic T. Tuberculosis trends in Central Serbia in the period 1956-1996. Int J Tuberc Lung Dis 2000;4:32-5.

3. Corbett E., Watt C., Walker N., et al. The growing burden of tuberculosis: Global trends and interactions with the HIV epidemic. Arch Intern Med 2003;163:1009-21.

4. Standaert B., Niragira F., Kadende P., Piot P. The association of tuberculosis and HIV-1 infection in Burundi. AIDS Res Hum Retroviruses 1989;5:247-51.
5. Caylà J.A., García de Olalla P., Galdós-Tangüis H., et al. The influence of intravenous drug use and HIV infection in the transmission of tuberculosis. AIDS 1996;10:95-100.

6. Oliveira H.B., Marín-León L., Cardoso J.C. Perfil de mortalidade de pacientes com tuberculose relacionada a comorbidade tuberculose-Aids. Rev Saúde Pública 2004;38(4):503-10.

7. Sacks L.V., Pendle S. Factors related to in-hospital deaths in patients with tuberculosis. Arch Intern Med 1998;158:1916-22.

8. Braun M.M., Cote T.R., Rabkin C.S. Trends in death with tuberculosis during AIDS era. JAMA 1993;269:2865-8.

9. Franco J., Blanquer R. Mortality from tuberculosis in Spain from 1970 to 1993: changes in epidemiology trends during the acquired immune-deficiency syndrome epidemic. Int J Tuberc Lung Dis 1998;2:663-96.

10. Boerma J.T., Nunn A.J., Whitworth J.A. Mortality impact of the AIDS epidemic: evidence from community studies in less developed countries. AIDS 1998;12(Suppl 1):S3-14.

11. Brasil. AIDS Boletim Epidemiológico. Ano V n $01-27^{\mathrm{a}}$ a $52^{\mathrm{a}}$ semanas epidemiológicas - julho a dezembro de $2007-01^{\mathrm{a}}$ a $26^{\mathrm{a}}$ semanas epidemiológicas - janeiro a junho de 2008 / ISSN 15171159.

12. Camargo Jr., K.R., Coelli C.M. RecLink: aplicativo para o relacionamento de bases de dados, implementando o método probabilistic record linkage. Cad Saúde Pública $2000 ; 16(2): 439-47$.

13. Song A.T., Schout D., Novaes H.M., Goldbaum M. Clinical and epidemiological features of AIDS/tuberculosis comorbidity. Rev Hosp Clin Fac Med Sao Paulo 2003;58(4):207-14.

14. Laguardia J., Merchán-Hamann E. Risk factors for tuberculous disease in AIDS cases reported in Brazil, from 1980 to 2000. Rev Esp Salud Publica 2003;77(5):553-65.

15. Bates I., Fenton C., Gruber J., et al. Vulnerability to malaria, tuberculosis, and HIV/AIDS infection and disease. Part 1: determinants operating at individual and household level. Lancet Infect Dis 2004;4(5):267-77.

16. Silveira J.M., Sassi R.A., de Oliveira Netto I.C., Hetzel J.L. Prevalence of and factors related to tuberculosis in seropositive human immunodeficiency virus patients at a reference center for treatment of human immunodeficiency virus in the southern region of the state of Rio Grande do Sul, Brazil. J Bras Pneumol 2006;32(1):48-55. 
17. David A.M., Mercado S.P., Becker D., et al. The Prevention and Control of HIV/AIDS, TB and Vector-borne Diseases in Informal Settlements: Challenges, Opportunities and Insights. Journal of Urban Health: Bulletin of the New York Academy of Medicine 2007;84(1):i65-i74.

18. Lazaridis E.M. Database standardization, linkage, and the protection of privacy. Ann Intern Med 1997, 127 (8pt2): 696.

19. Silva, JPL; Travassos, C; Vaconcellos, MM; Campos, LM. Revisão sistemática sobre encadeamento ou linkage de bases de dados secundários para uso em pesquisa em saúde no Brasil. Cadernos de Saúde Coletiva 2006;14(2):197-224.

20. Lucena F.F., Fonseca M.G., Sousa A.I.U., Coeli C.M. O relacionamento de bancos de dados na implementação da vigilância da AIDS. Cadernos de Saúde Coletiva, 2006;14(2):305-12.

21. do Prado T.N., Galavote H.S., Brioshi A.P., et al. Epidemiological profile of tuberculosis cases reported among health care workers at the University Hospital in Vitoria, Brazil. J Bras Pneumol 2008;34(8):607-13.

22. Fonseca M.G., Travassos C., Bastos F.I., et al. Social distribution of AIDS in Brazil, according to labor market participation, occupation and socioeconomic status of cases from 1987 to 1998. Cad Saude Publica 2003;19(5):1351-63.
23. Muniyandi M., Ramachandran R., Balasubramanian R., Narayanan P.R. Socio-economic dimensions of tuberculosis control: review of studies over two decades from Tuberculosis Research Center. J Commun Dis 2006;38(3):204-15

24. Lönnroth K., Aung T., Maung W., et al. Social franchising of TB care through private GPs in Myanmar: an assessment of treatment results, access, equity and financial protection. Health Policy Plan $2007 ; 22(3): 156-66$.

25. Golub J.E., Saraceni V., Cavalcante S.C., et al. The impact of antiretroviral therapy and isoniazid preventive therapy on tuberculosis incidence in HIV-infected patients in Rio de Janeiro, Brazil AIDS 2007;21:1441-8.

26. Lawn S.D., Badri M., Wood R. Tuberculosis among HIVinfected patients receiving HAART: long term incidence and risk factors in a South African cohort. AIDS 2005; 19:2109-16.

27. Golub J.E., Bur S., Cronin W.A., et al. Delayed tuberculosis diagnosis and tuberculosis transmission. Int $\mathrm{J}$ Tuberc Lung Dis 2005;10(1):24-30. 